\title{
Immune genes are associated with human glioblastoma pathology and patient survival
}

Elodie Vauléon ${ }^{1,2^{*}}$, Avril Tony ${ }^{2,3}$, Abderrahmane Hamlat ${ }^{4}$, Amandine Etcheverry ${ }^{2,5,6}$, Dan Cristian Chiforeanu' Philippe Menei ${ }^{8}$, Jean Mosser ${ }^{2,5,6}$, Véronique Quillien ${ }^{2,3}$ and Marc Aubry ${ }^{6}$

\begin{abstract}
Background: Glioblastoma (GBM) is the most common and lethal primary brain tumor in adults. Several recent transcriptomic studies in GBM have identified different signatures involving immune genes associated with GBM pathology, overall survival (OS) or response to treatment.

Methods: In order to clarify the immune signatures found in GBM, we performed a co-expression network analysis that grouped 791 immune-associated genes (IA genes) in large clusters using a combined dataset of 161 GBM specimens from published databases. We next studied IA genes associated with patient survival using 3 different statistical methods. We then developed a 6-IA gene risk predictor which stratified patients into two groups with statistically significantly different survivals. We validated this risk predictor on two other Affymetrix data series, on a local Agilent data series, and using RT-Q-PCR on a local series of GBM patients treated by standard chemo-radiation therapy.

Results: The co-expression network analysis of the immune genes disclosed 6 powerful modules identifying innate immune system and natural killer cells, myeloid cells and cytokine signatures. Two of these modules were significantly enriched in genes associated with OS. We also found $108 \mathrm{IA}$ genes linked to the immune system significantly associated with OS in GBM patients. The 6-IA gene risk predictor successfully distinguished two groups of GBM patients with significantly different survival (OS low risk: 22.3 months versus high risk: 7.3 months; $p<0.001$ ). Patients with significantly different OS could even be identified among those with known good prognosis (methylated MGMT promoter-bearing tumor) using Agilent (OS 25 versus 8.1 months; $p<0.01$ ) and RT-PCR (OS 21.8 versus 13.9 months; $\mathrm{P}<0.05)$ technologies. Interestingly, the 6-IA gene risk could also distinguish proneural GBM subtypes.
\end{abstract}

Conclusions: This study demonstrates the immune signatures found in previous GBM genomic analyses and suggests the involvement of immune cells in GBM biology. The robust 6-IA gene risk predictor should be helpful in establishing prognosis in GBM patients, in particular in those with a proneural GBM subtype, and even in the well-known good prognosis group of patients with methylated MGMT promoter-bearing tumors.

Keywords: Glioblastoma, Immune system, Survival

\footnotetext{
* Correspondence: e.vauleon@rennes.unicancer.fr

'Department of Medical Oncology, Eugène Marquis Cancer Institute, rue de

la bataille Flandres Dunkerque, Rennes 35042, France

${ }^{2}$ CNRS UMR 6061 Genetic and Development, University of Rennes 1, Rennes,

France

Full list of author information is available at the end of the article
}

\section{Biomed Central}

(c) 2012 Vauleon et al.; licensee BioMed Central Ltd. This is an Open Access article distributed under the terms of the Creative Commons Attribution License (http://creativecommons.org/licenses/by/2.0), which permits unrestricted use, distribution, and reproduction in any medium, provided the original work is properly cited. 


\section{Background}

Glioblastoma multiforme (GBM) is the most common and aggressive primary brain tumor in adults. Despite recent advances in multimodal therapy, prognosis remains limited [1]. Conventional treatment, generally maximal safe surgical resection followed by combination radiation and chemotherapy with temozolomide, fails to prevent tumor recurrence.

Recently, molecular subtypes of brain tumors have been characterized by microarray gene expression profiles [2-6]. These subgroups have been associated with significant differences in tumor aggressiveness, progression, and/or prognosis [7]. Gene expression analysis has been reported as being more accurate than conventional histology $[8,9]$. Due to this greater accuracy, expression-based classifications offer an opportunity to improve molecular classification of gliomas [6,7] and clinical diagnosis of glioblastomas [2]. Such advances could be helpful in designing future therapeutic trials $[4,10]$.

Many arguments have supported a link between the immune system and glioma pathogenesis. In several epidemiologic studies, glioma incidence is inversely associated with allergy history [11-13]. T-lymphocyte infiltration has been reported in certain glioma patients and an elevated number of intratumoral effector $\mathrm{T}$ cells has been recently correlated with a better survival in GBM patients [14].

Interestingly, several transcriptomic studies using microarray technologies have also reported an immune signature in gene expression profiling of glioma $[8,10,15,16]$ and GBM [17-20]. A signature associated with myeloid/macrophagic cells has been reported in most of these studies $[10,15,16,18,20]$, a finding consistent with the known macrophage/microglia infiltration in GBM [21-23]. More recently, transcriptomic studies in glioma have revealed different signatures involving immune genes associated with overall survival (OS) $[8,10,15,19]$. Gravendeel et al. reported an immune response signature associated with poor survival in glioma (Cluster 23 - the M function category) [8]. Murat et al. reported better outcome in patients with gene clusters characterizing features of innate immune response and macrophages (G24 cluster - 134 probes, among them probes for $C D 11 b$ and $C D 163$ genes) [19]. In contrast, Irliev et al. found an immune module (M7 module) associated with short survival that includes 449 genes, among them T-cell markers (CD4, CD8) and myeloid markers (MHC class II, TLR1 and TLR2) [15]. An NK cell signature (G12 gene cluster including Fc gamma receptors and DAP-12) has previously been reported in one study with higher level expression in primary GBM with shorter survival compared to low grade astrocytomas and secondary GBM [10].

In order to clarify the possible role of immune cells in GBM pathology and OS, we have performed a co-expression network analysis focusing on 791 genes linked to the immune system. Using a meta-analysis approach and independent validation cohorts, we identified an immune signature of GBM linked to innate immunity involving myeloid and NK cells as well as a 6-immune genes risk-model stratifying patients into two groups with significantly different OS.

\section{Methods}

\section{Immune-associated (IA) genes}

Immune-associated genes were defined as genes annotated with the 'immune system process' Gene Ontology (GO) biological process term (GO:0002376) by the AmiGO annotation tool (505 genes). Important immuneassociated genes not annotated with GO:0002376 in GO, such as cytokines, cells markers and immunomodulation genes (286 genes), were added to this GO genes list. This IA genes list is composed of 791 genes (Figure 1) (Additional file 1: Table S1).

\section{Patients and datasets}

For the survival analysis we used four publicly available Affymetrix technology independent microarray datasets (Figure 1) [2,5,7,24]. Moreover, a local cohort including 41 patients with newly diagnosed grade IV glioma admitted to the neurosurgery department of Rennes and Angers University Hospitals was analyzed using a different technology (Agilent). Eventually, a local cohort of 57 newly diagnosed GBM patients, admitted to the neurosurgery department of Rennes University Hospital and homogeneously treated by surgery and radio-chemotherapy with temozolomide like Stupp's schedule, was analyzed by a reverse transcriptase quantitative polymerase chain reaction (Q-PCR). All patients of the local cohort signed their informed consent. All cohorts and patients characteristics are detailed in Table 1.

The MGMT status of the local cohort was obtained by pyrosequencing methylation assay with a threshold of CpG methylation set to $\geq 9 \%[25,26]$. Local tumor subtypes were determined using the centroid-based classification algorithm described by Verhaak et al. [7].

\section{Weighted gene co-expression network analysis (WGCNA)}

Signed weighted gene co-expression network analysis was performed on the GSE13041 data set [24] (Figure 1 and Table 1). A co-expression network was constructed on the basis of the IA genes. For all possible pairs of the variable genes, Pearson correlation coefficients were calculated across all samples. The correlations matrix was raised to the power 6 , thus producing a weighted network. The weighted network was transformed into a network of topological overlap (TO) - an advanced co-expression measure that considers not only the correlation of 2 genes with each other, but also the extent of their shared correlations 


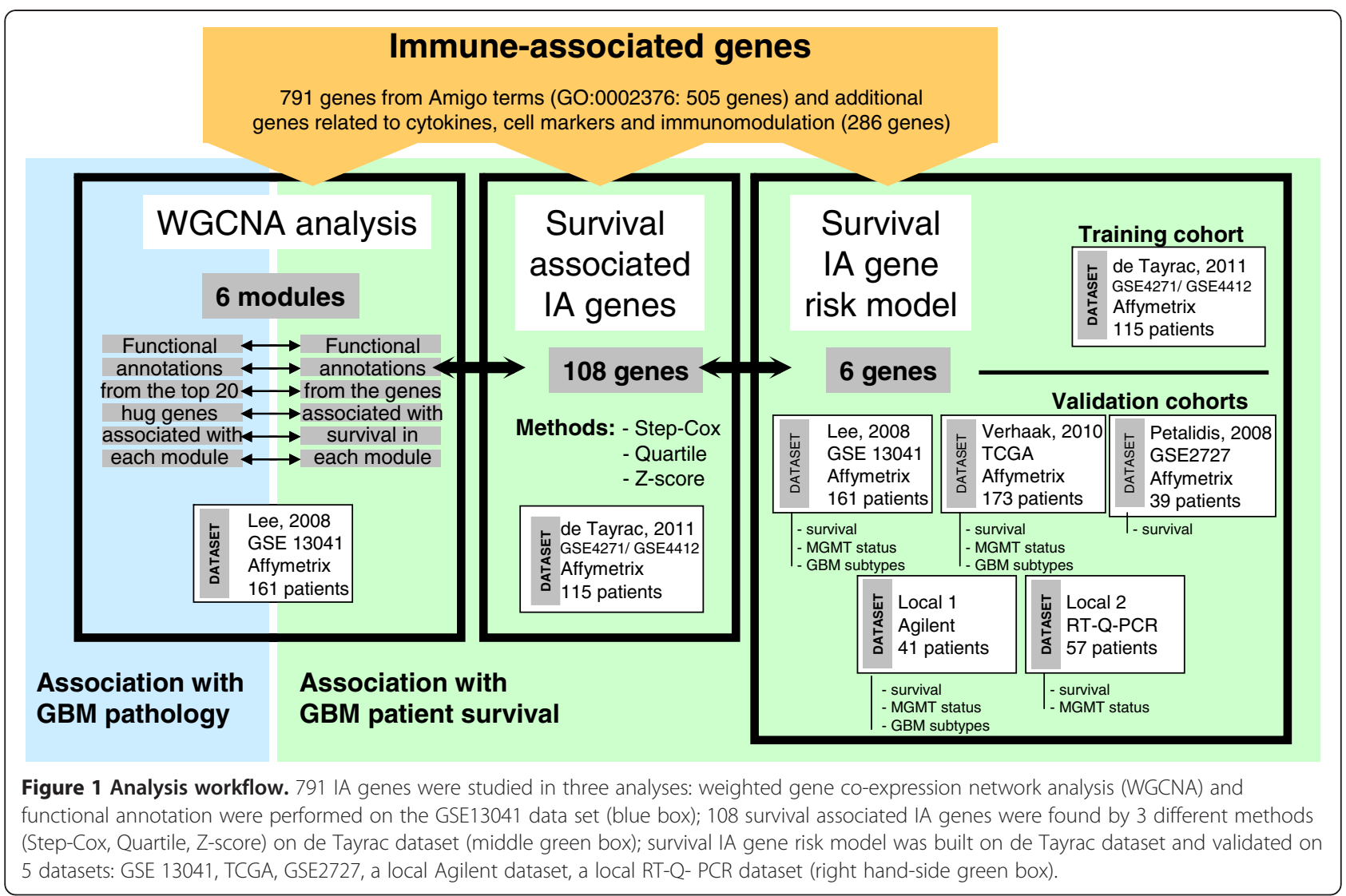

across the weighted network. Genes were hierarchically clustered on the basis of their TO. Modules were identified on the dendrogram using the Dynamic Tree Cut algorithm [27]. Each gene's connectivity was determined within its module of residence by summing up the TOs of the gene with all the other genes in the module. By definition, highly connected (hub) genes display expression profiles highly characteristic for their module of residence [28]. To define a measure of prognostic significance, a univariate Cox proportional hazards regression model was used to regress patient survival on the individual gene expression profiles. The resulting $\mathrm{p}$-values were used to define a measure of prognostic significance. To obtain a condensed representative profile of each module, focus was placed on the top 20 hub genes in the module. Co-expression network analyses were performed using the WGCNA R package. Survival analyses were performed using the survival $\mathrm{R}$ package.

\section{WGCNA modules functional annotation and enrichment}

Functional annotation of the IA genes co-expression modules was performed on the basis of the analysis of their top 20 hub genes and survival associated genes in each module. DAVID software (http://david.abcc.ncifcrf. gov/) was used to test each module for genome enrichment in GO process terms, PIR superfamily, Panther or Kegg pathways, InterPro or SwissProt keywords, and to test IA genes having an impact on overall survival (Fisher's exact tests with Benjamini-Hochberg correction for multiple testing).

\section{IA genes associated with patient outcome}

Molecular screening of IA genes was performed on 115 GBM patients included in a whole-genome Affymetrix meta-analysis dataset described by de Tayrac et al. [2]. Association between expression levels and patient outcome defined IA genes having an impact on overall survival (OS). Several survival analysis methods were used to identify relevant associations: (i) a Cox-step method [29], (ii) a differential analysis between the first and the fourth quartile, (iii) a classical Cox analysis (Figure 1). Adjusted p-values were calculated by controlling for the false discovery rate with the Benjamini-Hochberg correction. Overall survival was estimated by the Kaplan Meier method. Comparisons between survival groups were performed by the log-rank test. Univariate cox analyses were performed with gene expression data as a predictor and overall survival in months as the response.

\section{IA genes risk model}

An optimal survival model was built on IA genes associated with survival as described in de Tayrac et al. [2]. Analyses were performed using survival, survivalROC and 
Table 1 Characteristic of patients and datasets

\begin{tabular}{|c|c|c|c|c|c|c|c|}
\hline \multicolumn{2}{|l|}{$\begin{array}{l}\text { Name } \\
\text { Dataset origin }\end{array}$} & \multirow{2}{*}{$\begin{array}{l}\text { de Tayrac } \\
\text { GSE4271 } \\
\text { GSE4412 } \\
\text { Affymetrix }\end{array}$} & \multirow{2}{*}{$\begin{array}{c}\text { Lee } \\
\text { GSE13041 } \\
\text { Affymetrix }\end{array}$} & \multirow{2}{*}{$\begin{array}{c}\text { Verhaak } \\
\text { TCGA Data } \\
\text { Portal } \\
\text { Affymetrix }\end{array}$} & \multirow{2}{*}{$\begin{array}{l}\text { Petalidis } \\
\text { GSE2727 } \\
\text { Affymetrix }\end{array}$} & \multirow{2}{*}{$\begin{array}{c}\text { Local_1 } \\
\text { CHU Rennes } \\
\text { CHU Angers } \\
\text { Agilent }\end{array}$} & \multirow{2}{*}{$\begin{array}{c}\begin{array}{c}\text { Local_2 } \\
\text { CHU Rennes }\end{array} \\
\text { Q-PCR }\end{array}$} \\
\hline Technology & & & & & & & \\
\hline Number of samples & & 115 & 161 & 173 & 39 & 41 & 57 \\
\hline \multirow[t]{2}{*}{ Gender } & Male & M:65 & M:96 & M:112 & M:29 & $M: 21$ & $\mathrm{M}: 31$ \\
\hline & Female & $F: 50$ & $F: 65$ & $F: 61$ & $F: 10$ & $F: 20$ & $F: 26$ \\
\hline \multirow[t]{3}{*}{ Age (y) } & median [min-max] & 48 [18-82] & 55 [22-86] & 59 [14-87] & $61[22-74]$ & 58 [33-80] & 59 [36-78] \\
\hline & $<50$ & 65 & 59 & 56 & 14 & 10 & 10 \\
\hline & $>=50$ & 50 & 102 & 117 & 25 & 31 & 47 \\
\hline \multirow[t]{4}{*}{ KPS (\%) } & median & - & - & 90 [40-100] & - & 80 [40-100] & 80 [40-100] \\
\hline & $<=70$ & - & - & 22 & - & 15 & 28 \\
\hline & $>70$ & - & - & 58 & - & 23 & 29 \\
\hline & NA & - & - & & - & 3 & - \\
\hline \multirow[t]{4}{*}{ Treatment (surgical) } & biopsy & - & - & 6 & & 1 & 2 \\
\hline & partial resection & - & - & - & & 8 & 17 \\
\hline & total resection & - & $161(a)$ & 164 & (c) & 26 & 38 \\
\hline & NA & - & - & 1 & & 6 & - \\
\hline \multirow[t]{3}{*}{ Treatment (adjuvant) } & RT & - & & & & 3 & - \\
\hline & RT + CT like Stupp's schedule & - & (b) & (b) & (c) & 37 & 57 \\
\hline & no treatment & - & & & & 1 & - \\
\hline \multirow[t]{3}{*}{ MGMT status } & Methylated & - & 86 & 42 & - & 24 & 27 \\
\hline & Un-methylated & - & 75 & 122 & - & 17 & 29 \\
\hline & NA & - & - & - & - & - & 1 \\
\hline \multirow[t]{3}{*}{ IDH1 status } & Wild-type & - & - & 167 & - & 39 & 39 \\
\hline & Mutated & - & - & 6 & - & 2 & 1 \\
\hline & NA & - & - & - & - & - & 17 \\
\hline \multirow[t]{2}{*}{ Subtype } & Proneural & - & 41 & 48 & - & 12 & - \\
\hline & non-Proneural & - & 120 & 125 & - & 29 & - \\
\hline
\end{tabular}

(a) 'resection mentioned alone with no other details.

(b) Excessively heterogeneous treatment. GBM de novo tumors with no prior treatment.

(c) Data not available.

rbsurv $\mathrm{R}$ packages. These packages selected survivalassociated genes and estimated the regression coefficients of the optimal survival model after adjustment on the study factor. All analyses were stratified on the age.

\section{Q-PCR procedures}

Total RNA was isolated using Rneasy Plus Mini QIAGEN kit from fresh-frozen glioblastoma samples. RNA integrity was confirmed using the Agilent Bioanalyser (RNA 6000 NAno assay kit). cDNA synthesis was obtained by a High capacity cDNA Reverse Transcription kit with Rnase inhibitor (Applied biosystem ${ }^{\circledR}$ ). Q-PCR reactions were done with the 7900HT Fast Real-time PCR System using the Applied biosystem $^{\circledR}$ Taq Man FAM-labeled probes for ACVR2, CD22, MNX1, ARG1, RPS19 and FGF2, and the three housekeeping genes: TBP, HPRT1, GAPDH. Liver cells, testis cells, B lymphocytes and U251 cells were used as positive control. The relative amounts of the gene transcripts were determined using the $\Delta \Delta \mathrm{Ct}$ method, as described by the manufacturer.

\section{Results}

\section{IA genes co-expression modules}

WGCNA algorithm with the Lee dataset (GSE 13041) was applied to explore transcriptional relationships between IA genes and highlight consistent patterns of gene coexpression [24]. The weighted gene co-expression network constructed on the basis of the IA genes revealed 6 modules, each of them containing coordinately expressed genes potentially involved in shared cellular processes. To associate putative relevant processes and structures with the observed gene co-expression, we analyzed the functional enrichment of each module. For each module, the top five hub IA genes and the first five genes associated with 
survival are provided in Figure 2. The modules' annotations were obtained with the top 20 hub IA genes associated with each module and all IA genes associated with survival within this module (Figure 2). The IA genes co-expression modules were thus designated as followed: NK cells and innate immunity (blue module), Cytokines and molecular
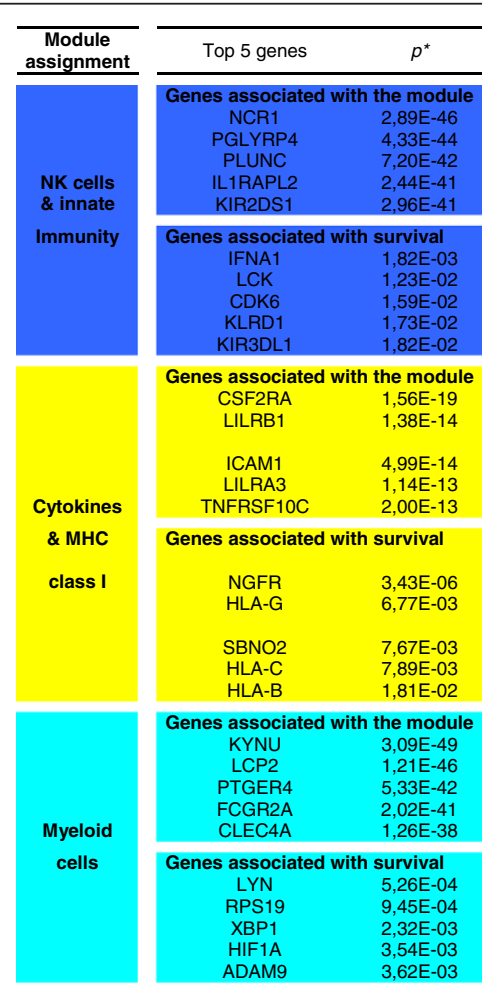

Genes associated with the module CSF2RA $1,56 \mathrm{E}-19$ ICAM1 4,99E-14 LILRA3 $\quad 1,14 \mathrm{E}-13$ TNFRSF10C associated with survival

$\begin{array}{ll}\text { NGFR } & 3,43 \mathrm{E}-06 \\ \text { HLA-G } & 6,77 \mathrm{E}-03 \\ & \\ \text { SBNO2 } & 7,67 \mathrm{E}-03 \\ \text { HLA-C } & 7,89 \mathrm{E}-03 \\ \text { HLA-B } & 1,81 \mathrm{E}-02\end{array}$

Genes associated with the module KYNU 3,09E-49 LCP2 PTGER4 FCGR2A 1,21E-46

Genes associated with survival LYN 5,26E-04 RPS19 XBP1 $9,45 \mathrm{E}-04$ HIF1A
ADAM9 2,32E-03
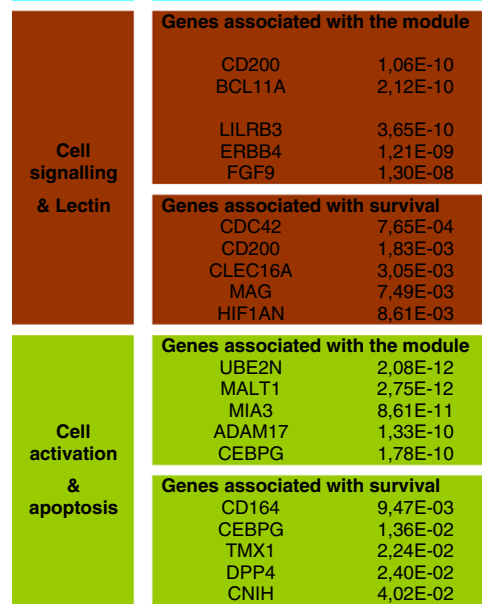

\begin{tabular}{cr} 
CD164 & $9,47 \mathrm{E}-03$ \\
CEBPG & $1,36 \mathrm{E}-02$ \\
TMX1 & $2,24 \mathrm{E}-02$ \\
DPP4 & $2,40 \mathrm{E}-02$ \\
\hline
\end{tabular}

$\begin{array}{ll}\text { CNIH } & 2,40 \mathrm{E}-02 \\ & 4,02 \mathrm{E}-02\end{array}$
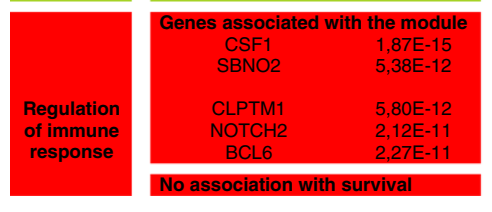
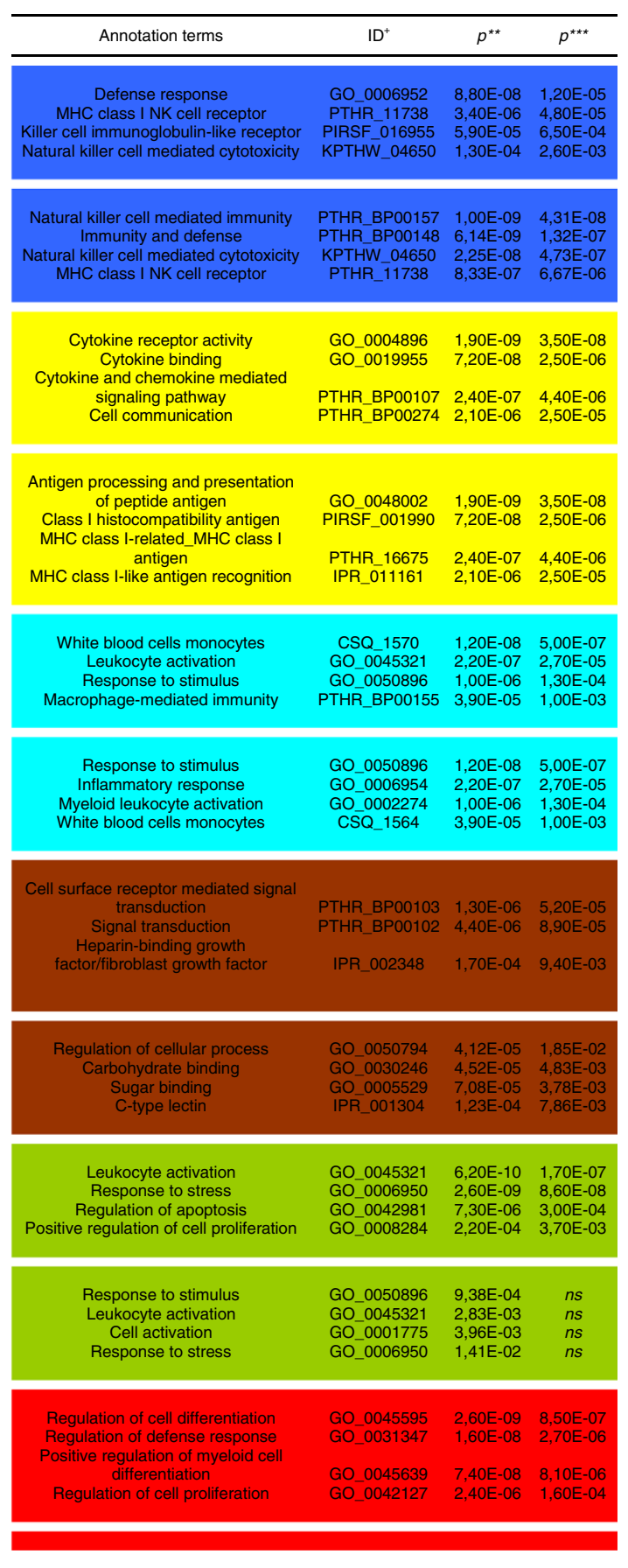

Figure 2 Gene annotations of the GBM co-expression modules. Annotations of the top 20 hub genes and survival associated genes in each module were tested for genome enrichment in Gene Ontology process terms (GO), PIR superfamily (PIRSF), Panther (PTHR) or KEGG (KPTHR) pathways, InterPro (IPR) keywords or CGAP Sage tissue expression data (CSQ) using the DAVID program (http://david.abcc.ncifcrf.gov/). $p$ values were calculated for gene association to the module $\left(^{*}\right)$ and module annotations (** for $p$ and *** Benjamini $p$ values). 
histocompatibility complex (MHC) class I (yellow module), Myeloid cells (turquoise module), Cell signaling and lectin (brown module), Cell activation and apoptosis (green module) and Regulation of immune response (red module).

\section{IA genes associated with survival}

Interestingly, two co-expression modules were significantly enriched in IA genes having an impact on overall survival: NK cells and innate immunity signature module and the Cytokines and MHC class I signature module $(\mathrm{p}<0.01)$.

Three different methods were then applied to further analyze the IA genes associated with survival using the de Tayrac dataset. The step-Cox model identified 52 genes associated with overall survival. The quartile model found 46 genes significantly differentially expressed between the lowest survivors and the highest survivors. The classical Cox method identified 28 genes associated with patient outcome (Additional file 1: Table S2). The overlap between the three methods is presented in Figure 3. In conclusion, 108 out of 791 IA genes were found to be associated with GBM patient survival by at least one of the three different statistical methods.

\section{Risk-score model of IA genes as a GBM outcome predictor}

An optimal survival model was built on IA genes associated with survival as described in de Tayrac et al. [2].
The mathematical model included 6 genes: ACVR2A, CD22, MNX1, ARG1, RPS19, FGF2 previously identified as described above. This risk-score equation based on the expression of these 6 genes can be written $(0.744 \times \mathrm{CD} 22)+(2.109 \times \mathrm{ACVR} 2 \mathrm{~A})+(0.860 \times \mathrm{MNX} 1)$ $+(-1.328 \times$ RPS19 $)+(-1.028 \times$ FGF2 $)+(0.913 \times$ ARG1 $)$. A risk-score greater than or equal to the threshold of 0.30 signifies a high-risk patient with poor prognosis. Prognosis power is positive with expression of 4 genes (ACVR2A, CD22, MNX1, ARG1) and negative with expression of two others (RPS 19, FGF2).

The risk-model (threshold $=0.30$ ) stratified the training cohort (de Tayrac dataset) [2] into 2 groups with a significant difference in $\mathrm{OS}(\mathrm{p}=4.0 \mathrm{E}-13)$. The low-risk $(\mathrm{n}=66)$ and high-risk $(\mathrm{n}=49)$ groups had a median OS of 22.3 and 7.3 months, respectively. Stratification of the validation cohort (GSE 2727 published by Petalidis et al. [5]) led to a significant difference of OS (low risk group $(\mathrm{n}=18)$ : 12 months versus high risk group $(\mathrm{n}=21)$ : 6 months; $\mathrm{p}=1.2 \mathrm{E}-4)$. The robustness of the 6 -IA gene risk-score equation was also checked by using 2 external and publicly available studies performed on Affymetrix technologies (Table 1). The predictor identified two groups of patients with a significant difference in OS using the GSE13041 cohort [24] $(\mathrm{p}<0.001)$ and the TCGA cohort [7] $(\mathrm{p}<0.01)$. Median OS and number of patients in each risk category are provided in Figure 4.
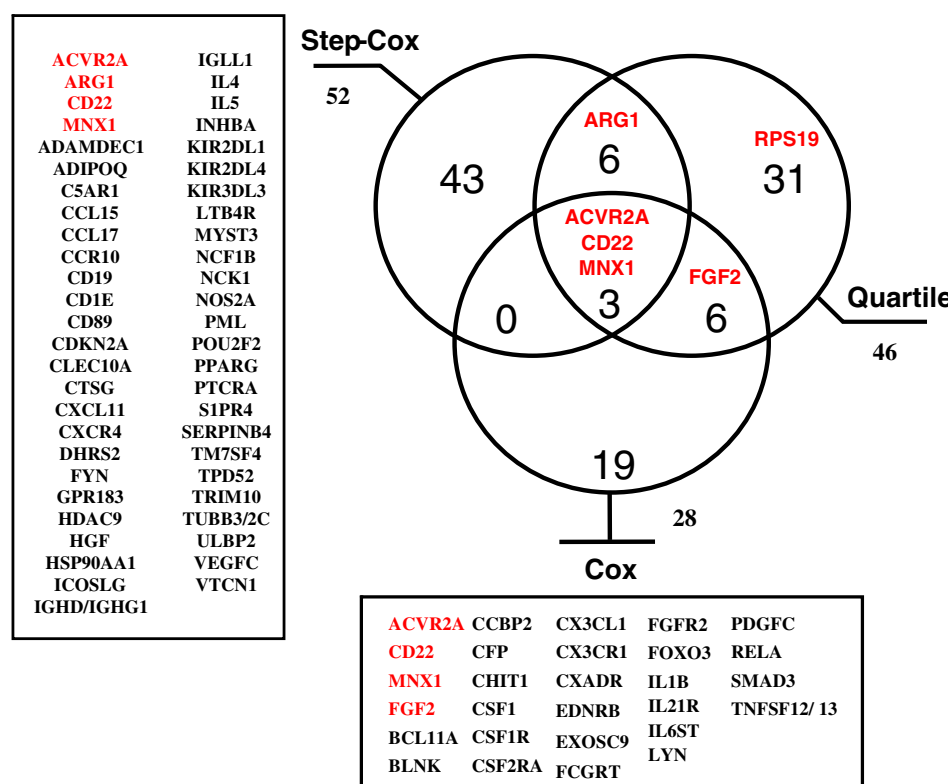

\begin{tabular}{|ll|}
\hline ACVR2A & IGSF6 \\
ARG1 & IKBKG \\
CD22 & IL21R \\
FGF2 & IL33 \\
IL5 \\
MNX1 & IL6ST \\
RPS19 & JAG2 \\
LDB1 \\
BMPR1A & MAP4K2 \\
BNIP3L & MET \\
C1QBP & MS4A1 \\
NCK1 \\
CALCA & PDGFC \\
CARTPT & PML \\
CCL17 & RBP4 \\
CD247 & SCYE1 \\
CD70 & TAPBP \\
CD79B & TGFB1 \\
TNFRSF25 \\
CRHR1 & TNFRSF6 \\
EDNRB & TNFSF12/ \\
ERAP1 & ULBP2 \\
FCGR1B/ C ZEB1 \\
FGF12 & \\
HIF1A & \\
HMGB1 & \\
\hline
\end{tabular}

Figure 3 Venn diagram of IA genes associated with survival in the statistical methods. 108 survival associated IA genes were found by 3 different methods (Step-Cox, Quartile, Z-score) on de Tayrac dataset. The 6 genes of IA risk model were written in red. 


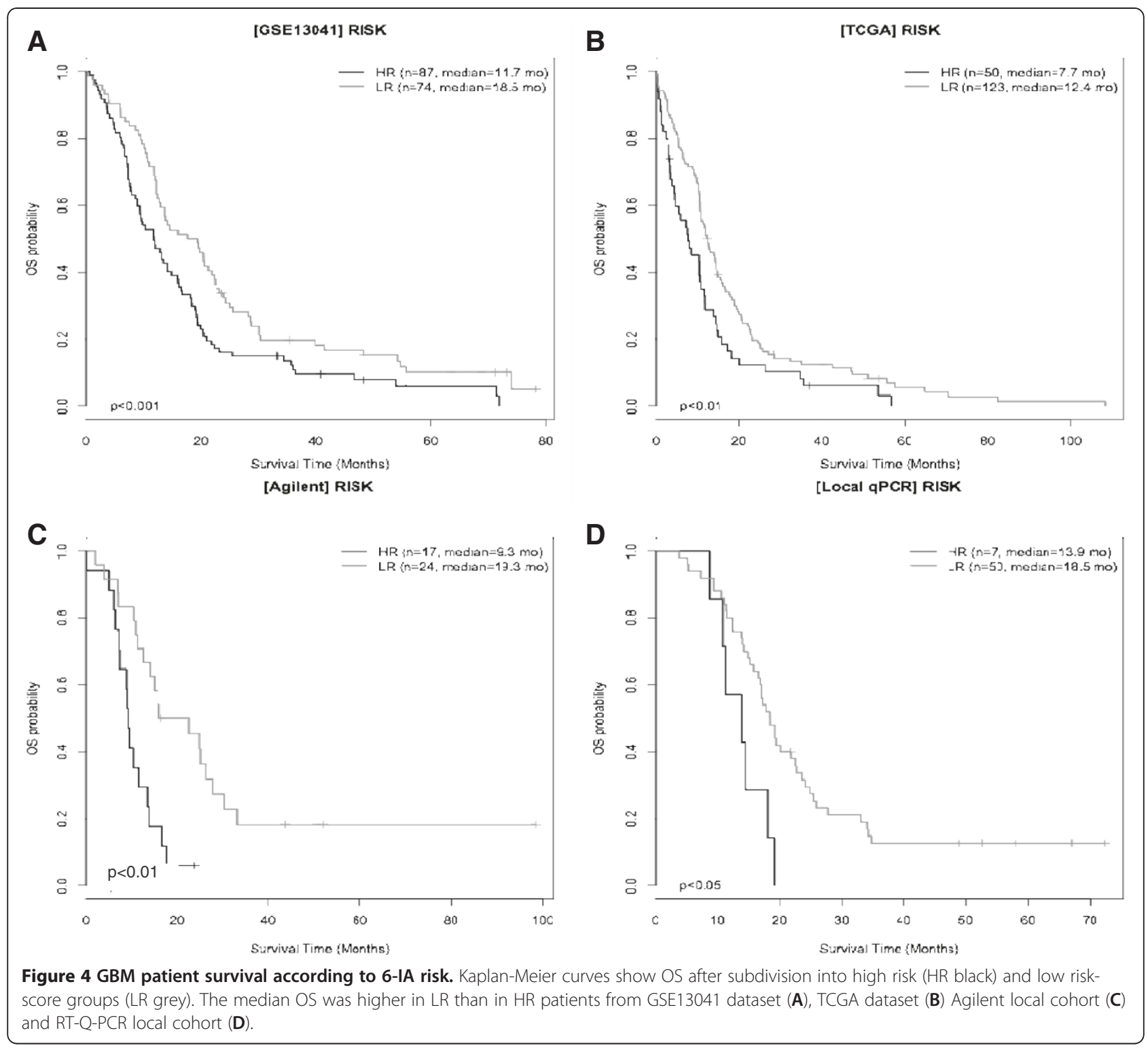

The performance of the 6-IA gene risk model was further tested on a local cohort of 41 patients using Agilent expression microarrays. Low-risk patients had a significantly better survival than high-risk patients (median OS of 19.3 months versus 9.3 months respectively; $\mathrm{p}<0.01$; Figure 4C). Eventually, reverse transcription Q-PCR based expression measurement of the 6-IA gene risk model genes was performed on a local cohort of 57 patients treated homogenously. Low-risk patients had also a significantly better survival than high-risk patients (median OS of 18.5 months versus 13.9 months respectively; $\mathrm{p}<0.05$; Figure $4 \mathrm{D}$ ).

IA genes risk-score model and MGMT methylation status In univariate Cox analysis using the de Tayrac dataset, the only factors associated with survival were the
MGMT promoter methylation status and the 6-IA gene risk category. Sex, histology, age and KPS were not statistically associated with patient outcome. In multivariate analysis, the $M G M T$ promoter methylation status and the 6-IA gene risk category were still significant $(\mathrm{p}=0.02$ and $p=0.01$, respectively). Difference of survival defined by the 6-IA gene risk remained significant when considering patients bearing tumors with methylated MGMT promoters ( 25 versus 8.1 months, $\mathrm{n}=8$ and 16 respectively, $\mathrm{p}<0.01$; Figure $5 \mathrm{C}$ ), as in the Lee dataset (21.2 versus 13.1 months, $\mathrm{p}<0 ; 05$, Figure $5 \mathrm{~A}$ ). In the Q-PCR cohort, the MGMT status and the 6-IA gene risk category were also significantly associated with OS of GBM patients, in both univariate and multivariate analysis $(\mathrm{p}=0.045$ and $\mathrm{p}=0.036$, respectively). Nineteen patients with low risk had a median survival of 21.8 months 


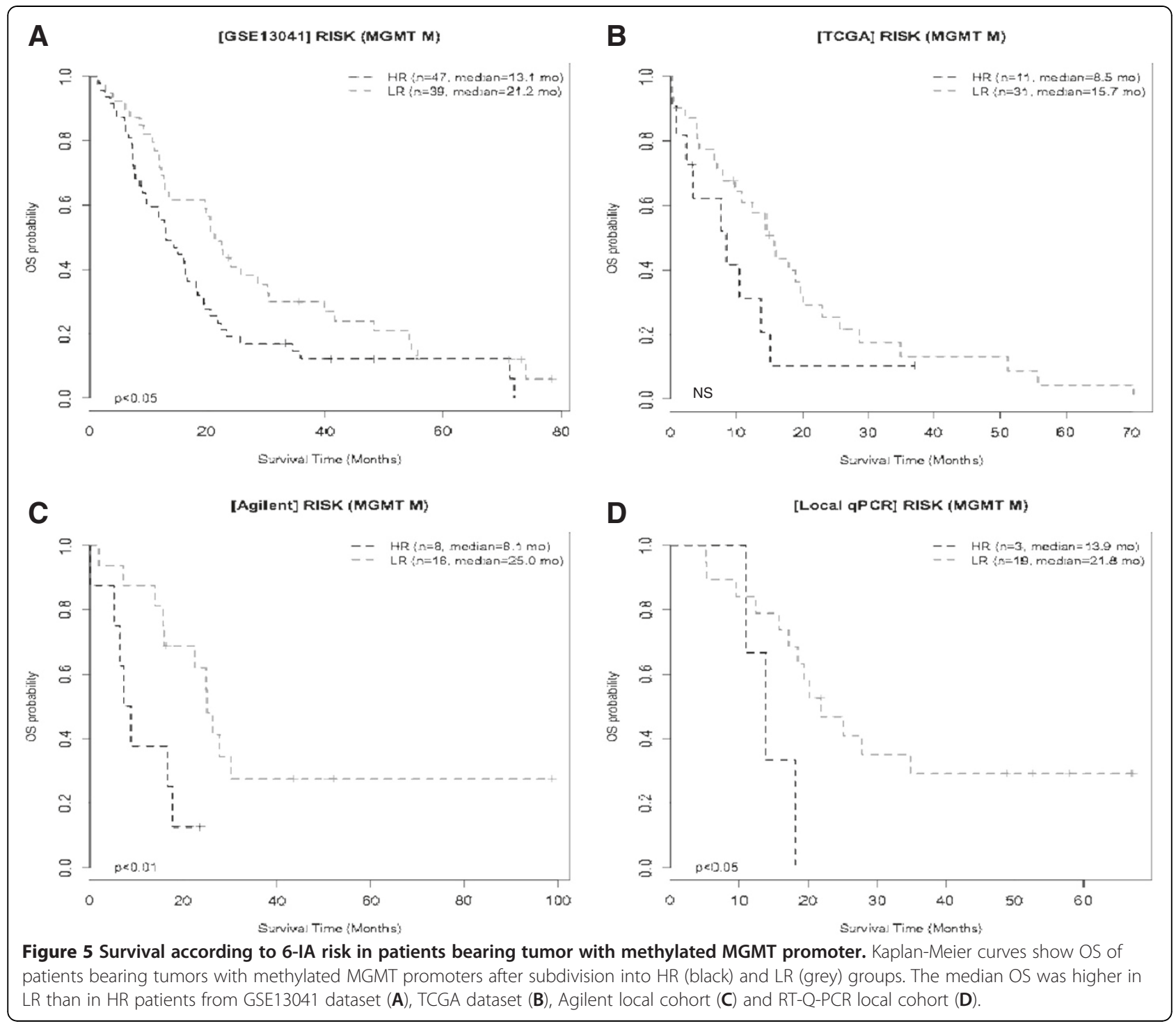

versus 13.9 months in three patients with high risk. Although the number of high-risk patients is low, the difference remains significant $(p<0.05$; Figure $5 \mathrm{D})$. No significant difference in survival could be found among patients bearing tumors with methylated MGMT promoters only in the TCGA cohort (Figure 5B). This might be explained by insufficient statistical power, especially since a significant difference was found in the 122 unmethylated MGMT promoter tumors from the TCGA cohort (data not shown).

\section{IA genes risk-score model and GBM subtypes}

The 6-IA gene risk predictor was also applied to a local cohort and to the cohorts described by Lee and Verhaak $[7,24]$ taking into account the recent GBM classification published by Phillips and Verhaak [6,7]. As only the proneural subtype is associated to survival [24], GBM specimens were divided into two sub-groups: proneural (25\% in GSE13041, 38\% in TCGA, 29\% in the local cohort) and non proneural (Table 1). The 6-IA gene risk predictor classed the patients with proneural GBM into two groups exhibiting significant OS difference: 11.9 versus 28.7 months $(\mathrm{p}<0.01$; [24]); 11.3 versus 3.4 months ( $p<0.05,[7]) ; 24.8$ versus 4.7 months $(\mathrm{p}<0.02$; in our local cohort) (Figure 6 A-C). Conversely, no difference was observed in the non proneural group of GBM (Figure 6 D-F).

\section{Discussion}

In this study, we were able to link IA genes expression pattern with GBM biology and patient survival. Indeed, our co-expression network analysis highlighted clusters of IA genes and revealed related immune signatures marking innate immunity, NK and myeloid cells and 


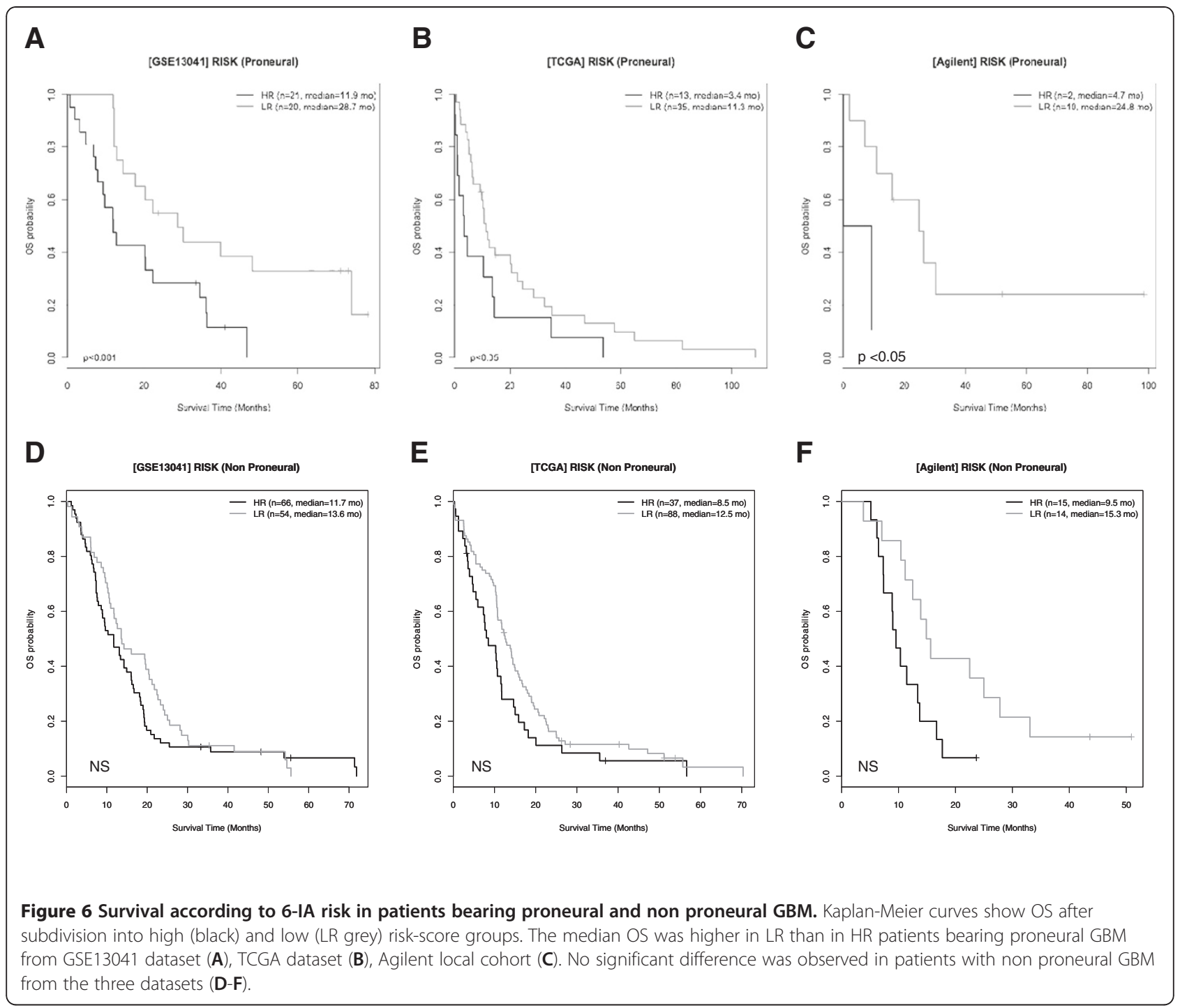

cytokines/MHC class I molecules profiles. Furthermore, 108 IA genes were associated with OS. Among these, 6 IA genes were included in a weighted multigene risk model that can predict outcome in GBM patients.

Several studies have previously reported an immune signature in GBM $[8,10,15-17,19,20,30]$. A signature associated with myeloid/macrophagic cells was reported in most of these $[10,15,16,18,20]$. We also found such a signature linked to one co-expression module for which annotation enrichment found monocytes, leukocyte activation and macrophage-mediated immunity. The well known macrophage/microglia infiltration in GBM can account for up to one-third of cells in some GBM specimens [21-23]. Unlike Ivliev et al. [15], we were unable to identify a T-cell signature in our analysis. Nevertheless, the association of two gene modules with GBM patient survival suggests that innate immunity including NK cell functions and cytokines/CMH class I profiles might affect outcome in GBM patients. A NK cell signature has previously been reported in one study in primary GBM [10]. NK cell infiltration was described earlier in glioma [31] but was not confirmed by others [32]. It is noteworthy that in murine glioma models, various vaccines strategies using CCL2 [33], CpG [34], IL12expressing stroma cells [35] or IL23-expressing dendritic cells [36], induced an increased recruitment of NK cells at the tumor site, associated with better overall survival.

Most of chemokines present in the cytokines/MHC class I module are involved in recruiting $\mathrm{T}$ cells, monocytes/ macrophages and neutrophils: e.g. CX3CR1/CX3CL1, CXCL9 and CXCR2 genes. In addition, most of the cytokines found such as MIF, IL5, IL12A and IL16 genes are known to regulate macrophages/monocytes, eosinophils, NK and T cells. Lohr has also reported that intratumoral 
infiltration of effector $\mathrm{T}$ cells is associated with a better survival in GBM [14]. In total, one could speculate that these two modules associated with overall survival reflect the recruitment and activation of immune cells such as NK cell, $\mathrm{T}$ cell, macrophages/monocytes, or neutrophils that would interfere with GBM patients' survival. Interestingly, several clinical trials using dendritic cells have reported that the presence of T cells and neutrophils at the tumor site is associated with longer survival of the vaccinated patients [37]. Recently, Ducray et al. reported that infiltration of both CD3+ T cells and CD68+ macrophages was observed more frequently in GBM responders than in non-responders to radiotherapy [17]. However, in the present study, we did not find any association between key regulators of the $\mathrm{T}$ cell biology such as GATA3, TBX21 (TBET), and RORC (RORgamma-t) with patients' survival (data not shown). The small amount of these infiltrating cells is usually reported in the GBM specimens and might have impaired the identification of such genes by a transcriptomic approach.

In addition to the co-expression network analysis, we have found 108 IA genes directly associated with OS in GBM patient using three different statistical methods. These genes are known to be involved in the biology of $\mathrm{B}$ cells (i.e. immunoglobulins, BLNK, CD19, CD20 and CD22 genes), T cells (i.e. CD1E, PTCRA, CD247), NK cells (i.e. KIR2DL1, KIR2DL4 and KIR3DL3 genes), and myeloid cells including monocytes/macrophages (i.e. $A D A M D E C 1$, CD89/FCAR, CD64/FCGR1B and FCGR1C genes) and neutrophils (i.e. $C D 89$, and $N C F 1 B$ genes). Surprisingly, other important genes expressed by glioma-infiltrating microglia/macrophages, such as CD163 and AIF1 (IBA1), were not significantly associated with patients' survival (data not shown). Komohara et al. have recently reported that the presence of CD163+ CD204+ M2-type macrophagic cells correlates with glioma grading and survival using an immunohistochemistry approach [38]. This discrepancy between our results and the Komohara et al. study could be explained by the fact that we used different technical approaches to detect these markers: at the mRNA level in our genomic study and at the protein level in [38]. Others genes of chemokines and cytokines have been also found such as CCL15, CCL17 IL1B and IL5 genes. Finally, some genes are known to be involved in the modulation/suppression of the immune response such as APRIL, ARG1, CD70, B7-H4, ICOSLG, NOS2A, TGFB1 and TWEAK genes.

Finally, we have developed a 6-IA-gene risk predictor of OS in GBM patients. The genes have been selected for an optimal survival model built on IA genes associated with survival as described in de Tayrac et al. [2]. This 6-IA gene risk is able to discriminate patients treated by chemo-radiation therapy into two distinct groups with significantly different survivals. These genes ACVR2A, ARG1, CD22, FGF2, MNX1 and RPS19 were present in all but one of the co-expression modules. The 'regulation of immune response' module, which contains no gene retained in the 6-IA-gene risk predictor, is the only one that does not include survival-associated genes. ACVR2A, CD22 and MNX1 genes were found to be associated with GBM patient survival in the three different statistical methods. Intriguingly, these 6 IA genes are not specific markers for known immune cell subpopulations. They are involved in the activation or the inhibition of the immune system. As a result, they impact positively or negatively on the risk predictor. For example, the expression of ARG1, a gene involved in immunosuppression, contributes positively to the 6-IA-gene risk index and therefore decreases the patient's probability of survival. Although these genes are known in other cancers, they have not been described in GBM. ACVR2A is a receptor for activin-A and controls cell proliferation [39], for example proliferation of prostate cancer cells [40]. Mutations of ACVR2A are commonly found in unstable colonic cancers [41], and interestingly, infiltration of CD3 $\mathrm{T}$ cells is associated with mutated ACVR2A genes [42]. ARG1 for arginase-1 is a cytosolic enzyme that hydrolyses arginine to urea and ornithine [43]. ARG1 has recently been involved in immunosuppressive mechanisms by reducing T-cell activation [44]. CD22 cannot be considered only to be a B cell receptor that mediates cell adhesion and signaling $[45,46]$ since Mott et al. report that neurons can secrete this molecule [47]. Neuronal secretion of CD22 inhibits microglia activation via interaction with CD45 [47]. FGF2 for fibroblast growth factor-2 stimulates GBM growth [48]. Nevertheless, the high molecular weight FGF2 isoform inhibits glioma proliferation [49] and explains the radiation therapy resistance pathway [50]. Interestingly, plasma levels of FGF are higher in GBM patients compared to control [51]. MNX1 gene is involved in a congenital malformation, the Currarino syndrome (congenital malformation) [52] and also previously reported in CD34+ cells, B cells and B lymphoid tissues [53]. MNX1 function in immune cells and GBM biology has not been demonstrated yet but it has recently been described as a transcriptional factor implicated in the development of both solid and hematological cancers [54]. RPS19 is a subunit of $40 \mathrm{~S}$ ribosome involved in pre-rRNA processing but also has extra-ribosomal functions. Indeed, RPS19 can act as a chemokine that regulates macrophage migration inhibitory factor (MIF) negatively [55]. Moreover, RPS19 can interact with FGF2 to drive differentiation or proliferation pathways of various cell types [56]. Only one statistical method, the quartile method, found this gene significantly (Figure 3), but the co-expression module found it to be significantly associated with OS (Figure 2). 
To validate the strength of our 6-IA-gene risk predictor, expression of these genes was tested in a local cohort using RT Q-PCR. This technique has at least two advantages, it is used routinely in most laboratories and is relatively inexpensive compared with genomic microarray technologies. The test cohort was small (57 GBM specimens) but homogeneous in terms of treatment: combined surgery and chemo-radiation therapy [1]. In addition, the MGMT methylation status, which is the best predictor of response to the current combination treatment, was determined for all GBM specimens. Applied to this small cohort, 6-IA-gene risk predictor was even able to discriminate significantly between patients with high and low risk in the good prognosis group, defined by methylation of the MGMT promoter.

Recent advances in glioma classification have been achieved using genomic analysis. It is now accepted that GBM can be categorized in four subtypes defined as proneural, neural, mesenchymal, and classical groups $[6,7,24]$. The clinical outcome of the patients is different according to the GBM subtype. For instance, patients with proneural subtype live longer and the standard treatment does not increase their overall survival $[6,7]$. In contrast, overall survival of patients with classical or mesenchymal subtype is significantly increased with the standard treatment. Interestingly, we have shown that our 6-IA-gene risk predictor was powerful in GBM proneural subtype but not in others subtypes. GBM proneural is an atypical GBM subtype which is associated with younger age, PDGFRA gene amplification, IDH1 mutations, TP53 mutations [7]. Due to the fact that these patients with proneural GBM have longer survival, one could speculate that the anti-tumor immune response could have more time to occur and slow down the tumor progression in some of these patients with a particular immune profile, revealed by our 6-AI-gene risk predictor.

\section{Conclusions}

In conclusion, we have demonstrated that GBM are characterized by an immune signature which could reflect the infiltration and activation of immune cells or the immunosuppression mechanisms developed by the tumor itself. Several IA genes were found to be associated with clinical outcome of GBM patients, allowing us to describe a 6-IA-gene risk predictor. This risk model can discriminate between patients with different outcomes, even within the good prognosis group based on MGMT status and within the proneural GBM subtype group. Further studies are needed to understand how these IA genes are involved in the control of GBM progression. Overall, this study highlights the important role of the immune system in the battle against the tumor and suggests new strategies for further development of immunotherapy for GBM patients.

\section{Additional file}

Additional file 1: Table S1. List of IA genes. Table S2. IA genes associated with survival in the 3 statistical methods.

\section{Competing interests}

No potential conflicts of interest were disclosed.

\section{Authors' contributions}

EV carried out the molecular studies, performed the statistical analysis, made the interpretation of the data and drafted the manuscript; TA participated in the design of the study, helped to draft the manuscript; and made the interpretation of the data; $\mathrm{AH}$ and PM provided GBM specimens and participated to the draft of manuscript; AE carried out the Agilent local microarray assays and helped to draft the manuscript; DCC reviewed the histopathology of GBM specimens; JM and VQ contributed to the conception and the design of the study and revised critically the manuscript; MA performed the statistical analysis, made the interpretation of the data, contributed to the conception and the design of the study and revised critically the manuscript. All authors read and approved the final manuscript.

\section{Grant support}

This work was supported by Gefluc Rennes Bretagne (Groupement des Entreprises Françaises dans la Lutte contre le Cancer) et la Région Bretagne (CPER « Biothérapies »).

\section{Acknowledgements}

We thank Michèle Marty for her excellent technical assistance; and the medical staff of the Neurosurgery departments of the CHU Rennes and Angers for their contribution. G. Pope has post-edited the English style.

\section{Author details}

${ }^{1}$ Department of Medical Oncology, Eugène Marquis Cancer Institute, rue de la bataille Flandres Dunkerque, Rennes 35042, France. ${ }^{2}$ CNRS UMR 6061 Genetic and Development, University of Rennes 1, Rennes, France.

${ }^{3}$ Department of Clinical Biology, Eugène Marquis Cancer Institute, Rennes, France. ${ }^{4}$ Department of Neurosurgery, University Hospital Rennes, Rennes, France. ${ }^{5}$ Medical Genomics Unit, Molecular Genetics and Genomics, University Hospital Rennes, Rennes, France. ${ }^{6}$ Biogenouest ${ }^{\circledR}$ Genomics Health Platform, University of Rennes 1, Rennes, France. ${ }^{7}$ Department of Pathology, University Hospital Rennes, Rennes, France. ${ }^{8}$ Department of Neurosurgery,

University Hospital Angers, Angers, France.

Received: 2 February 2012 Accepted: 6 August 2012

Published: 14 September 2012

\section{References}

1. Stupp R, Mason WP, van den Bent MJ, Weller M, Fisher B, Taphoorn MJ, Belanger K, Brandes AA, Marosi C, Bogdahn U, et al: Radiotherapy plus concomitant and adjuvant temozolomide for glioblastoma. N Engl J Med 2005, 352:987-996.

2. De Tayrac M, Aubry M, Saikali S, Etcheverry A, Surbled C, Guenot F, Galibert MD, Hamlat A, Lesimple T, Quillien V, et al: A 4-gene signature associated with clinical outcome in high-grade gliomas. Clin Cancer Res 2011, 17:317-327.

3. Freije WA, Castro-Vargas FE, Fang Z, Horvath S, Cloughesy T, Liau LM, Mischel PS, Nelson SF: Gene expression profiling of gliomas strongly predicts survival. Cancer Res 2004, 64:6503-6510.

4. Li A, Walling J, Ahn S, Kotliarov Y, Su Q, Quezado M, Oberholtzer JC, Park J, Zenklusen JC, Fine HA: Unsupervised analysis of transcriptomic profiles reveals six glioma subtypes. Cancer Res 2009, 69:2091-2099.

5. Petalidis LP, Oulas A, Backlund M, Wayland MT, Liu L, Plant K, Happerfield L, Freeman TC, Poirazi P, Collins VP: Improved grading and survival prediction of human astrocytic brain tumors by artificial neural network analysis of gene expression microarray data. Mol Cancer Ther 2008, 7:1013-1024. 
6. Phillips HS, Kharbanda S, Chen R, Forrest WF, Soriano RH, Wu TD, Misra A, Nigro JM, Colman H, Soroceanu L, et al: Molecular subclasses of highgrade glioma predict prognosis, delineate a pattern of disease progression, and resemble stages in neurogenesis. Cancer Cell 2006, 9:157-173.

7. Verhaak RG, Hoadley KA, Purdom E, Wang V, Qi Y, Wilkerson MD, Miller CR, Ding L, Golub T, Mesirov JP, et al: Integrated genomic analysis identifies clinically relevant subtypes of glioblastoma characterized by abnormalities in PDGFRA, IDH1, EGFR, and NF1. Cancer Cell 2010, 17:98-110.

8. Gravendeel LA, Kouwenhoven MC, Gevaert O, de Rooi JJ, Stubbs AP, Duijm JE, Daemen A, Bleeker FE, Bralten LB, Kloosterhof NK, et al: Intrinsic gene expression profiles of gliomas are a better predictor of survival than histology. Cancer Res 2009, 69:9065-9072.

9. Nutt CL, Mani DR, Betensky RA, Tamayo P, Cairncross JG, Ladd C, Pohl U, Hartmann C, McLaughlin ME, Batchelor TT, et al: Gene expression-based classification of malignant gliomas correlates better with survival than histological classification. Cancer Res 2003, 63:1602-1607.

10. Godard S, Getz G, Delorenzi M, Farmer P, Kobayashi H, Desbaillets I, Nozaki M, Diserens AC, Hamou MF, Dietrich PY, et al: Classification of human astrocytic gliomas on the basis of gene expression: a correlated group of genes with angiogenic activity emerges as a strong predictor of subtypes. Cancer Res 2003, 63:6613-6625.

11. Lachance DH, Yang P, Johnson DR, Decker PA, Kollmeyer TM, McCoy LS, Rice T, Xiao Y, li-Osman F, Wang F, et al: Associations of high-grade glioma with glioma risk alleles and histories of allergy and smoking. Am J Epidemiol 2011, 174:574-581.

12. Schlehofer B, Blettner M, Preston-Martin S, Niehoff D, Wahrendorf J, Arslan A, Ahlbom A, Choi WN, Giles GG, Howe GR, et al: Role of medical history in brain tumour development. Results from the international adult brain tumour study. Int J Cancer 1999, 82:155-160.

13. Zhou M, Wiemels JL, Bracci PM, Wrensch MR, McCoy LS, Rice T, Sison JD, Patoka JS, Wiencke JK: Circulating levels of the innate and humoral immune regulators CD14 and CD23 are associated with adult glioma. Cancer Res 2010, 70:7534-7542.

14. Lohr J, Ratliff T, Huppertz A, Ge Y, Dictus C, Ahmadi R, Grau S, Hiraoka N, Eckstein V, Ecker RC, et al: Effector T-cell infiltration positively impacts survival of glioblastoma patients and is impaired by tumor-derived TGFbeta. Clin Cancer Res 2011, 17:4296-4308.

15. Ivliev AE, 't Hoen PA, Sergeeva MG: Coexpression network analysis identifies transcriptional modules related to proastrocytic differentiation and sprouty signaling in glioma. Cancer Res 2010, 70:10060-10070

16. Shirahata M, Iwao-Koizumi K, Saito S, Ueno N, Oda M, Hashimoto N, Takahashi JA, Kato K: Gene expression-based molecular diagnostic system for malignant gliomas is superior to histological diagnosis. Clin Cancer Res 2007, 13:7341-7356.

17. Ducray F, De RA, Chinot O, Idbaih A, Figarella-Branger D, Colin C, KarayanTapon L, Chneiweiss H, Wager M, Vallette F, et al: An ANOCEF genomic and transcriptomic microarray study of the response to radiotherapy or to alkylating first-line chemotherapy in glioblastoma patients. Mol Cancer 2010, 9:234.

18. Liang Y, Diehn M, Watson N, Bollen AW, Aldape KD, Nicholas MK, Lamborn $K R$, Berger MS, Botstein D, Brown PO, et al: Gene expression profiling reveals molecularly and clinically distinct subtypes of glioblastoma multiforme. Proc Natl Acad Sci USA 2005, 102:5814-5819.

19. Murat A, Migliavacca E, Gorlia T, Lambiv WL, Shay T, Hamou MF, De TN, Regli L, Wick W, Kouwenhoven MC, et al: Stem cell-related "self-renewal" signature and high epidermal growth factor receptor expression associated with resistance to concomitant chemoradiotherapy in glioblastoma. J Clin Onco 2008, 26:3015-3024.

20. Tso CL, Freije WA, Day A, Chen Z, Merriman B, Perlina A, Lee Y, Dia EQ Yoshimoto K, Mischel PS, et al: Distinct transcription profiles of primary and secondary glioblastoma subgroups. Cancer Res 2006, 66:159-167.

21. Avril T, Vauleon E, Tanguy-Royer S, Mosser J, Quillien V: Mechanisms of immunomodulation in human glioblastoma. Immunotherapy 2011, 3:42-44.

22. Graeber MB, Scheithauer BW, Kreutzberg GW: Microglia in brain tumors. Glia 2002, 40:252-259.

23. Roggendorf W, Strupp S, Paulus W: Distribution and characterization of microglia/macrophages in human brain tumors. Acta Neuropathol 1996, 92:288-293.
24. Lee Y, Scheck AC, Cloughesy TF, Lai A, Dong J, Faroogi HK, Liau LM, Horvath S, Mischel PS, Nelson SF: Gene expression analysis of glioblastomas identifies the major molecular basis for the prognostic benefit of younger age. BMC Med Genomics 2008, 1:52.

25. Dunn J, Baborie A, Alam F, Joyce K, Moxham M, Sibson R, Crooks D, Husband D, Shenoy A, Brodbelt A, et al: Extent of MGMT promoter methylation correlates with outcome in glioblastomas given temozolomide and radiotherapy. Br J Cancer 2009, 101:124-131.

26. Karayan-Tapon L, Quillien V, Guilhot J, Wager M, Fromont G, Saikali S, Etcheverry A, Hamlat A, Loussouarn D, Campion L, et al: Prognostic value of O6-methylguanine-DNA methyltransferase status in glioblastoma patients, assessed by five different methods. J Neurooncol 2010, 97:311-322.

27. Langfelder $P$, Zhang $B$, Horvath S: Defining clusters from a hierarchical cluster tree: the Dynamic Tree Cut package for R. Bioinformatics 2008, 24:719-720

28. Horvath S, Dong J: Geometric interpretation of gene coexpression network analysis. PLoS Comput Biol 2008, 4:e1000117. doi:doi:10.1371/ journal.pcbi.1000117.

29. Cox DR: Regression models and life-tables. Journal of the Royal Statistical Society Series B (Methodological) 1972, 34:187-220.

30. Liau LM, Prins RM, Kiertscher SM, Odesa SK, Kremen TJ, Giovannone AJ, Lin JW, Chute DJ, Mischel PS, Cloughesy TF, et al: Dendritic cell vaccination in glioblastoma patients induces systemic and intracranial T-cell responses modulated by the local central nervous system tumor microenvironment. Clin Cancer Res 2005, 11:5515-5525.

31. Vaquero J, Coca S, Oya S, Martinez R, Ramiro J, Salazar FG: Presence and significance of NK cells in glioblastomas. J Neurosurg 1989, 70:728-731.

32. Sawamura Y, Abe H, Aida T, Hosokawa M, Kobayashi H: Isolation and in vitro growth of glioma-infiltrating lymphocytes, and an analysis of their surface phenotypes. J Neurosurg 1988, 69:745-750.

33. Nagai M, Masuzawa T: Vaccination with MCP-1 cDNA transfectant on human malignant glioma in nude mice induces migration of monocytes and NK cells to the tumor. Int Immunopharmacol 2001, 1:657-664.

34. Alizadeh D, Zhang L, Brown CE, Farrukh O, Jensen MC, Badie B: Induction of anti-glioma natural killer cell response following multiple low-dose intracerebral CpG therapy. Clin Cancer Res 2010, 16:3399-3408.

35. Hong X, Miller C, Savant-Bhonsale S, Kalkanis SN: Antitumor treatment using interleukin- 12-secreting marrow stromal cells in an invasive glioma model. Neurosurgery 2009, 64:1139-1146.

36. Hu J, Yuan X, Belladonna ML, Ong JM, Wachsmann-Hogiu S, Farkas DL, Black KL, Yu JS: Induction of potent antitumor immunity by intratumoral injection of interleukin 23-transduced dendritic cells. Cancer Res 2006, 66:8887-8896

37. Vauleon E, Avril T, Collet B, Mosser J, Quillien V: Overview of cellular immunotherapy for patients with glioblastoma. Clin Dev Immunol 2010, 2010:1-18. article ID 689171.

38. Komohara Y, Ohnishi K, Kuratsu J, Takeya M: Possible involvement of the M2 anti-inflammatory macrophage phenotype in growth of human gliomas. J Pathol 2008, 216:15-24.

39. Ying SY, Zhang Z, Furst B, Batres Y, Huang G, Li G: Activins and activin receptors in cell growth. Proc Soc Exp Biol Med 1997, 214:114-122.

40. Simon DP, Vadakkadath MS, Wilson AC, Gallego MJ, Weinecke SL, Bruce E, Lyons PF, Haasl RJ, Bowen RL, Atwood CS: Activin receptor signaling regulates prostatic epithelial cell adhesion and viability. Neoplasia 2009, 11:365-376.

41. Jung B, Gomez J, Chau E, Cabral J, Lee JK, Anselm A, Slowik P, ReamRobinson D, Messer K, Sporn J, et al: Activin signaling in microsatellite stable colon cancers is disrupted by a combination of genetic and epigenetic mechanisms. PLoS One 2009, 4:e8308.

42. Tougeron D, Fauquembergue E, Rouquette A, Le PF, Sesboue R, Laurent M, Berthet P, Mauillon J, Di FF, Sabourin JC, et al: Tumor-infiltrating lymphocytes in colorectal cancers with microsatellite instability are correlated with the number and spectrum of frameshift mutations. Mod Pathol 2009, 22:1186-1195.

43. Morris SM Jr: Recent advances in arginine metabolism: roles and regulation of the arginases. Br J Pharmacol 2009, 157:922-930.

44. Yachimovich-Cohen N, Even-Ram S, Shufaro Y, Rachmilewitz J, Reubinoff B: Human embryonic stem cells suppress $T$ cell responses via arginase Idependent mechanism. J Immunol 2010, 184:1300-1308. 
45. Tedder TF, Tuscano J, Sato S, Kehrl JH: CD22, a B lymphocyte-specific adhesion molecule that regulates antigen receptor signaling. Annu Rev Immunol 1997, 15:481-504.

46. Wilson $\mathrm{GL}$, Fox $\mathrm{CH}$, Fauci $\mathrm{AS}$, Kehrl JH: CDNA cloning of the $\mathrm{B}$ cell membrane protein CD22: a mediator of B-B cell interactions. J Exp Med 1991, 173:137-146.

47. Mott RT, It-Ghezala G, Town T, Mori T, Vendrame M, Zeng J, Ehrhart J, Mullan M, Tan J: Neuronal expression of CD22: novel mechanism for inhibiting microglial proinflammatory cytokine production. Glia 2004, 46:369-379.

48. Loilome W, Joshi AD, Ap Rhys CM, Piccirillo S, Vescovi AL, Gallia GL, Riggins GJ: Glioblastoma cell growth is suppressed by disruption of Fibroblast Growth Factor pathway signaling. J Neurooncol 2009, 94:359-366.

49. Lemiere S, Azar R, Belloc F, Gursel D, Pyronnet S, Bikfalvi A, Auguste P: Overexpression of high molecular weight FGF-2 forms inhibits glioma growth by acting on cell-cycle progression and protein translation. Exp Cell Res 2008, 314:3701-3711.

50. Cohen-Jonathan E, Toulas C, Monteil S, Couderc B, Maret A, Bard JJ, Prats H, Ly-Schveitzer N, Favre G: Radioresistance induced by the high molecular forms of the basic fibroblast growth factor is associated with an increased G2 delay and a hyperphosphorylation of p34CDC2 in HeLa cells. Cancer Res 1997, 57:1364-1370.

51. Salmaggi A, Eoli M, Frigerio S, Silvani A, Gelati M, Corsini E, Broggi G, Boiardi A: Intracavitary VEGF, bFGF, IL-8, IL-12 levels in primary and recurrent malignant glioma. J Neurooncol 2003, 62:297-303.

52. Lynch SA, Bond PM, Copp AJ, Kirwan WO, Nour S, Balling R, Mariman E, Burn J, Strachan T: A gene for autosomal dominant sacral agenesis maps to the holoprosencephaly region at 7q36. Nature Genet 1995, 11:93-95.

53. Harrison KA, Druey KM, Deguchi Y, Tuscano JM, Kehrl JH: A novel human homeobox gene distantly related to proboscipedia is expressed in lymphoid and pancreatic tissues. J Biol Chem 1994, 269:19968-19975.

54. Ferguson S, Gautrey HE, Strathdee G: The dual role of HLXB9 in leukemia. Pediatr Blood Cancer 2011, 56:349-352.

55. Filip AM, Klug J, Cayli S, Frohlich S, Henke T, Lacher P, Eickhoff R, Bulau P, Linder M, Carlsson-Skwirut C, et al: Ribosomal protein S19 interacts with macrophage migration inhibitory factor and attenuates its proinflammatory function. J Biol Chem 2009, 284:7977-7985.

56. Soulet F, Al ST, Roga S, Amalric F, Bouche G: Fibroblast growth factor-2 interacts with free ribosomal protein S19. Biochem Biophys Res Commun 2001, 289:591-596.

doi:10.1186/1755-8794-5-41

Cite this article as: Vauléon et al:: Immune genes are associated with human glioblastoma pathology and patient survival. BMC Medical Genomics 2012 5:41.

\section{Submit your next manuscript to BioMed Central and take full advantage of:}

- Convenient online submission

- Thorough peer review

- No space constraints or color figure charges

- Immediate publication on acceptance

- Inclusion in PubMed, CAS, Scopus and Google Scholar

- Research which is freely available for redistribution 